Document downloaded from:

http://hdl.handle.net/10251/148178

This paper must be cited as:

Mohan, P.; Elshalakany, AB.; Osman, T.; Amigó, V.; Mohamed, A. (2017). Effect of Fe content, sintering temperature and powder processing on the microstructure, fracture and mechanical behaviours of Ti-Mo-Zr-Fe alloys. Journal of Alloys and Compounds. 729:12151225. https://doi.org/10.1016/j.jallcom.2017.09.255

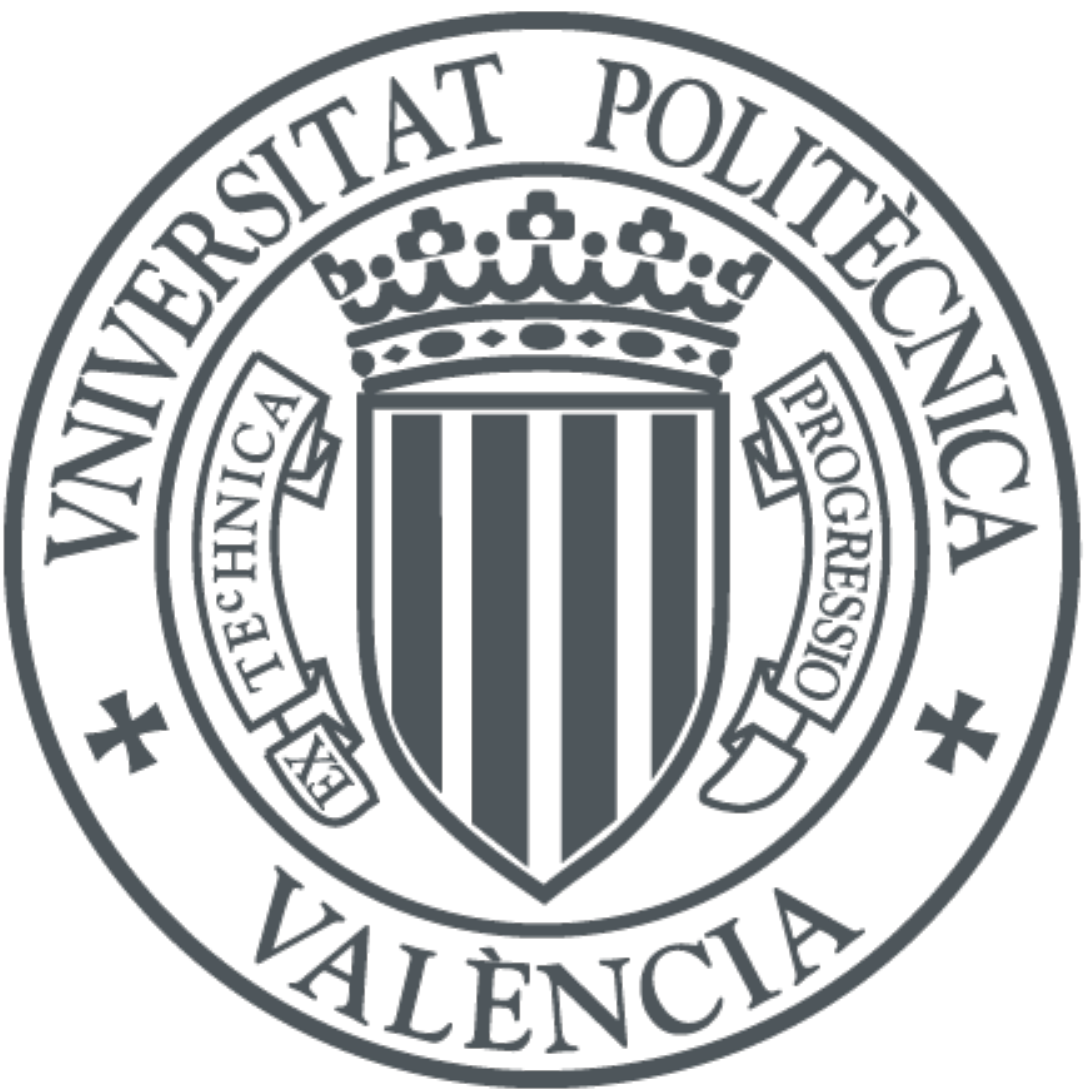

The final publication is available at

https://doi.org/10.1016/j.jallcom.2017.09.255

Copyright Elsevier

Additional Information 


\title{
Effect of Fe content, sintering temperature and powder processing on the microstructure, fracture and mechanical behaviours of Ti-Mo- Zr-Fe alloys
}

\author{
P.Mohan ${ }^{\text {, }}$ Abou Bakr Elshalakany ${ }^{1,4}$, T. A. Osman ${ }^{3}$, V.Amigo ${ }^{\text {1, }}$ Alaa Mohamed ${ }^{2,4, *}$ \\ ${ }^{1}$ Institute of Materials Technology Universitat Politècnica de València, Spain \\ ${ }^{2}$ Egypt Nanotechnology Center, EGNC, Cairo University, 12613 Giza, Egypt \\ ${ }^{3}$ Mechanical Design and Production Engineering Department, Cairo University, Giza, Egypt \\ ${ }^{4}$ Production Engineering and Printing Technology Department, Akhbar El Yom Academy, \\ Giza, Egypt
}

*Corresponding author: Dr. Alaa Mohamed

Email: alakha@kth.se

Phone: +201069676710

\begin{abstract}
The present work studies the effect of iron on the microstructural characterization and mechanical properties of Ti12Mo6ZrxFe alloys that fabricated by two different techniques elemental blend (EB) at $600 \mathrm{MPa}$ and mechanical alloying (MA) at 600 $\mathrm{MPa}$ and $900 \mathrm{MPa}$ with different sintering temperatures. The Ti12Mo6Zr $x \mathrm{Fe}(x=1$, 2, 3 and 4 wt.\%) alloys were investigated to develop new biomedical materials used for dental implant application. The microstructure, residual porosity and the mechanical properties of the sintered Ti12Mo6Zr $x$ Fe alloys were investigated by using optical microscopy, X-ray diffraction (XRD), Scanning Electron Microscopy (SEM), Energy dispersive X-ray (EDX), microhardness and bending stress-strain curves. The results indicated that addition of $\mathrm{Zr}$ and a small amount of Fe improves the $\beta$-phase stability and improving the properties of Ti-Mo alloy. In addition, with increasing the sintering temperatures, the microstructure became more homogeneous for $\beta$ phase, which decreases in the modulus and strength. The Mechanical alloying allows highly homogeneous composition and particle morphology. Bending strength in EB is much higher than MA techniques. Increasing of compaction pressure during MA technique increases the bending strength and decreases the porosity. Moreover, the Ti12Mo6Zr2Fe alloys exhibited higher bending strength/modulus ratios.
\end{abstract}

Key words: Elemental Blend; Mechanical Alloying; Biocompatibility; Mechanical properties.

\section{INTRODUCTION}

Powder Metallurgy (P/M) manufacturing process is one of the emerging fields for the production of complex geometries with tailor-made strength and high tolerances to be produced in one single operation without subsequent machining [1, 2]. P/M components are an established cost-effective process and low environmental impact to 
produce high strength parts. Thus, it has going to replace traditional methods of metal forming operations because of the added advantages like lesser energy consumption, maximum material utilization, low relative material wastage, and competitive cost [39].

Titanium and its alloys have been widely used for biomedical applications than both steels and aluminum alloys due to their light weight, high corrosion resistance, excellent biocompatibility and excellent mechanical properties [10-17]. Molybdenum (Mo) has a strong effect as beta stabilizer on titanium alloys in comparison with Ta or $\mathrm{Nb}$ elements, which is suitable biomedical uses. It has a high modulus of elasticity and has melting points lower only than tungsten and tantalum [18]. Moreover, it is a valuable alloy agent because it contributes to the hardening and toughness of steels. Therefore, the most important role of Mo in living organisms is as a metal heteroatom at the active site in the certain enzyme. In addition, zirconium $(\mathrm{Zr})$ is a neutral alloying element, does not alter the allotropic transition temperature of titanium, and is thus used as a hardening agent. Besides having complete solid solubility, zirconium has chemical and physical properties similar to titanium. The addition of this element causes increased resistance to corrosion; the alloy improves the biocompatibility and leads to a decrease in melting point [11, 16]. The use of Mo is more controversial, but some studies have demonstrated adequate mechanical compatibility and good cyto compatibility of $\mathrm{Ti}$ alloys containing Mo such as Ti-Mo, Ti-Mo-Ta or Ti-Mo-Zr-Fe. Moreover the addition of $\mathrm{Zr}$ and a small amount of $\mathrm{Fe}$ improves the $\beta$-phase stability, superior corrosion resistance compared to most other alloy systems, and improving the mechanical properties of Ti-Mo alloy [19]. Therefore, $\mathrm{Zr}$ is considered as an alloying element in most new developed Ti alloys for biomedical applications, such as in Ti$29 \mathrm{Nb}-13 \mathrm{Ta}-4.6 \mathrm{Zr}[20,21], \mathrm{Ti}-24 \mathrm{Nb}-4 \mathrm{Zr}-8 \mathrm{Sn}$ [22] and $\mathrm{Ti}-3 \mathrm{Zr}-2 \mathrm{Sn}-3 \mathrm{Mo}-25 \mathrm{Nb}$ alloys [23]. The previous researcher developed better biomaterials with Ti-15Mo, Ti13Nb-13Zr, Ti-12Mo-6Zr-2Fe, Ti-35Nb-5Ta-7Zr, Ti-29Nb-13Ta-4.6Zr Ti-12Mo$6 \mathrm{Zr}-2 \mathrm{Fe}, \mathrm{Ti}-15 \mathrm{Mo}-5 \mathrm{Zr}-3 \mathrm{Al}, \mathrm{Ti}-15 \mathrm{Mo}-3 \mathrm{Nb}-3 \mathrm{O}$, Ti-13Nb-13Zr, and $\mathrm{Ti}-35 \mathrm{Nb}-$ $5 \mathrm{Ta}-7 \mathrm{Zr}$ for biomedical application for achieving better mechanical properties [2439]. In addition, Fe has been selected due to its low cost as well as being one of the strongest $\beta$ phase stabilizers in titanium which makes it attractive because with small additions it should be possible to stabilize this phase in Ti-Nb alloys [29, 30]. However, they still might not be strong enough when compared to cortical bone [26]. In contrast, Ti12Mo6ZrxFe alloy was reported to achieve higher strength than unalloyed porous $\mathrm{Ti}$ at the same porosity $[40,41]$.

In this paper, we compared two techniques of compaction, elemental blend and mechanical alloying techniques for Ti12Mo6Zr2Fe alloy. MA is a solid-state powder processing technique involving repeated welding, fracturing, and rewelding of powder particles in a high-energy ball mill. MA has now been shown to be capable of synthesizing a variety of equilibrium and non-equilibrium alloy phases starting from blended elemental or pre alloyed powders. The purpose is to develop a new Ti alloys to satisfy high requirements of high hardness, high strength and low Young's modulus 
in biomedical applications, such as dental implant and hard tissue replacements. In this study, a series of Ti-Mo-Zr- xFe alloys were prepared and subjected to study the microstructure in detail by using optical and electron microscopy, XRD, SEM, and EDX. The effect of sintering temperature and Fe content on relative density and microstructures of Ti-Mo-Zr- xFe alloy was investigated. In addition, the effect of powder processing on total porosity and density of Ti-Mo-Zr- xFe alloy have been investigated. On the other hand, the mechanical properties have been evaluated according to the effect of sintering temperature, Fe content, and powder metallurgical processing techniques.

\section{EXPERIMENTAL PROCEDURE}

\subsection{MATERIALS AND PROCESSING TECHNIQUES}

Two different techniques of compaction, elemental blend and mechanical alloying techniques have been used for Ti12Mo6ZrxFe alloy. The different metal powders used for preparing Ti12Mo6ZrxFe are $\mathrm{Ti}, \mathrm{Mo}, \mathrm{Zr}$ and Fe. The properties of powders are shown in Table 1:

Table 1: Ti, Mo, $\mathrm{Zr}$ and Fe powder characteristics:

\begin{tabular}{|l|c|c|l|}
\hline Powder & Purity $(\%)$ & Powder size (mesh) & supplier \\
\hline Titanium & 99.7 & 325 & Alfa Aesar \\
\hline Molybdenum & 99.95 & 250 & Alfa Aesar \\
\hline Zirconium & 99.95 & 325 & Alfa Aesar \\
\hline Iron & 99.8 & 230 & Hoganas \\
\hline
\end{tabular}

The blend of elemental powders was conducted in a closed vial in a blender model Bioengineering Inversion for $30 \mathrm{~min}$ with the speed of $90 \mathrm{rpm}$. On the other hand, characterization of the mechanical alloying technique is listed below:

A) Machine type: Planetary ball mill; model 400/2 Retsch

B) Rotation speed: $180 \mathrm{rpm}$

C) Ball to powder weight ratio: 10:1

D) Material for vial and balls: $\mathrm{FeCr}$ steel

E) Ball weight for each run: $200 \mathrm{~g}$.

F) Powder weight for each run: $20 \mathrm{~g}$.

G) Milling atmosphere: Argon atmosphere

$\mathrm{H})$ Milling time: $45 \mathrm{~min}$ for preventing excessive temperature rise during milling

I) Cooling time: $20 \mathrm{~min}$.

The powders of the elemental blend and mechanical alloying were compacted in a universal testing machine Instron 432 Model with a load cell of $500 \mathrm{kN}$, with a compaction pressure of $600 \mathrm{MPa}$. The die used is rectangular with dimensions of $32 \times 12 \mathrm{~mm}$, for obtaining a height of $6 \mathrm{~mm}$ approximately, $8 \mathrm{~g}$ powder weight required approximately. Powder filling is done by hand in the die; Compaction is done by a uniaxial hydraulic press. Compaction pressure for elemental blend technique is $600 \mathrm{MPa}$ and for the mechanical alloying technique is $600 \mathrm{MPa}$ and 900 
$\mathrm{MPa}$. The specimens were sintered under high vacuum tubular furnace (approximately $10^{-4}$ to $10^{-5}$ mbar) in a Carbolite HVT $15 / 75 / 450$ model, at $1250{ }^{\circ} \mathrm{C}$ and $1300{ }^{\circ} \mathrm{C}$, after a dwell time of $3 \mathrm{~h}$, the samples were furnace cooled at $10^{\circ} \mathrm{C} / \mathrm{min}$.

\subsection{POWDER CHARACTERIZATION, MICROSTRUCTURE AND MECHANICAL PROPERTIES}

The microhardness of polished alloys was measured using a Matsuzawa MXT70 microhardness tester at a load of $200 \mathrm{~g}$ for $15 \mathrm{~s}$. The phase compositions of the alloys were examined by X-ray diffraction (XRD, D/Max-2550, Japan). A NOVATM Nano 230 scanning electron microscope (SEM) equipped with an energy dispersive X-ray (EDX) was used for morphological analysis. Ultrasonic test was done with Karl Deutsch digital Echograph for measuring elastic modulus. Specimens for phase identification were mechanically ground with silicon-carbide (SiC) paper to 2000 grits and then polished in a solution consisting of $10 \mathrm{vol} . \% \mathrm{HF}, 40 \mathrm{vol} . \% \mathrm{HNO}_{3}$ and 50 vol. $\% \mathrm{H}_{2} \mathrm{O}$. The grain size of the alloys was evaluated from SEM images. Threepoint bending tests were performed using a desktop mechanical tester (Shimadzu AGS-500D, Tokyo, Japan). Specimens with a gauge size of $3.1 \mathrm{~mm} \times 1.4 \mathrm{~mm} \times 8$ $\mathrm{mm}$ were sintered and polished to measure the tensile mechanical properties. To ensure the reproducibility, at least five points were conducted for each sample.

To characterize the microstructure, initially cut the transversal section of the sintered sample, mount the sample and then do metallographic preparation very well. The microstructure was observed using an optical microscope, Nikon LV100. For measuring overall porosity Archimedes test is suitable. For quantifying the ( $\alpha$ and $\beta$ phases) and internal porosity NIS-Elements ${ }^{\circledR}$ image analysis software was used. Backscattered electron images (BSE) and secondary electron image (SEI) of the microstructure at different magnifications were obtained in a scanning electron microscope. Microanalysis was performed by energy dispersive spectroscopy (EDS) for quantification of chemical composition, using an Oxford Instruments X-ray detector installed in the microscope. Fractography of the breaking sample also seen by SEM which we can analyze the fragile or ductility of the sample.

\section{RESULTS AND DISCUSSION}

\subsection{Powder characterization}

Fig. 1 shows the SEM images of mixing all-milled Ti12Mo6ZrxFe powder metallurgy with different magnification. The result shows that the mixing of powder by MA enhances the homogeneity of the powder. From Fig. 1(b), it is clear that cold deformation occurs after MA mixing. The distribution of the particle can easily see from Fig. 1(a) and the distribution of the elements into the particles, clearly shown by Fig. 1(b). The particle size distribution graphs of ball-milled Ti12Mo6Zr2Fe particles are shown in Fig. 1(c) and the average particle size was $400 \mu \mathrm{m}$. 

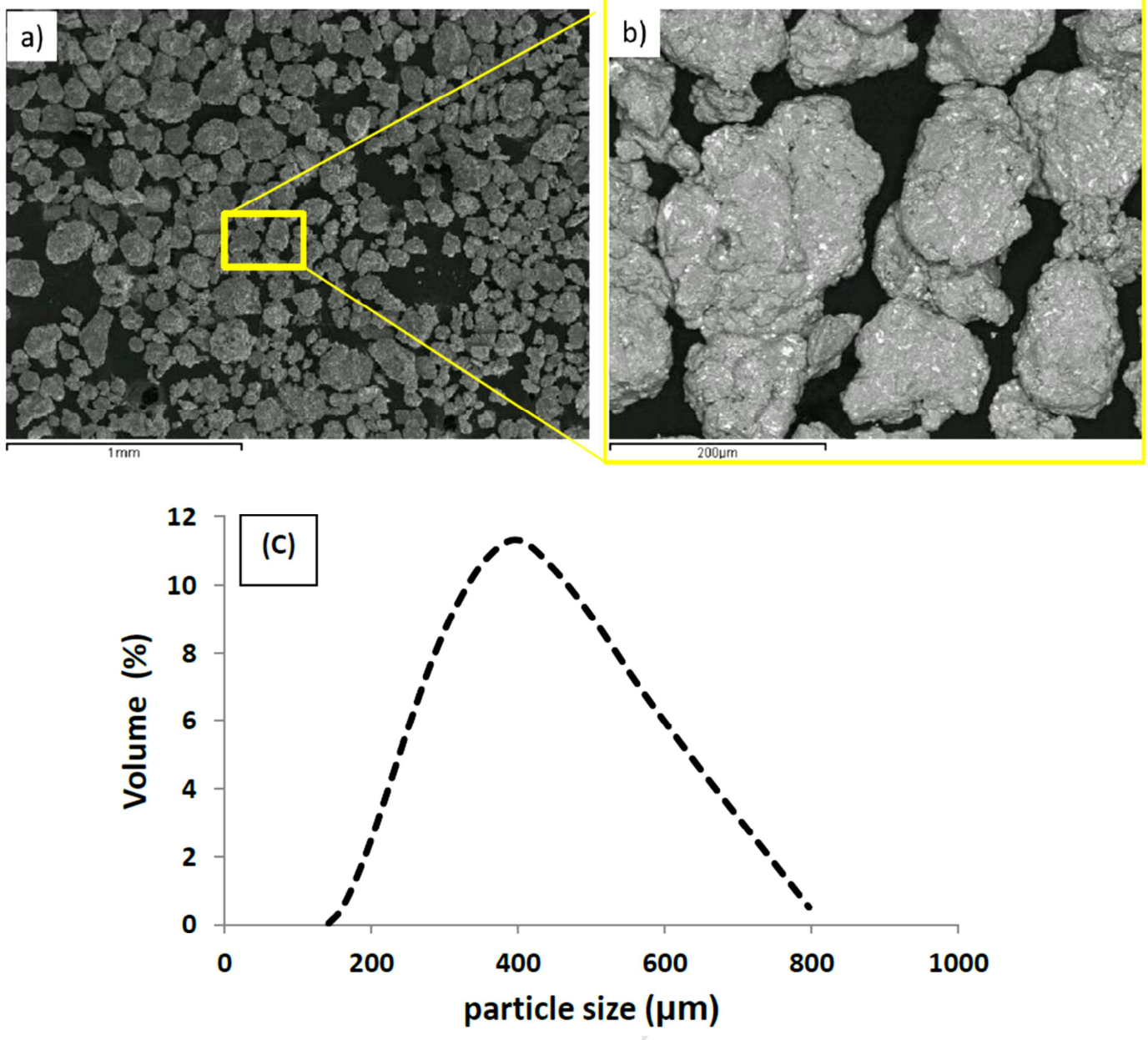

Fig. 1. SEM images of Ti12Mo6Zr2Fe powder by MA technique for $45 \mathrm{~min}$ (a) General aspect of the powder, secondary image (b) Detail of the powder, backscattered image, and (c) Particle size distribution of Ti12Mo6Zr2Fe powder.

\subsection{Phase identification}

Experimental results of this study indicate that the crystal structures of the Ti12Mo6Zr are strongly affected by the addition of Fe. Fig. 2 shows the XRD patterns of Ti12Mo6Zr and with a different addition of Fe alloys. The Ti12Mo6Zr alloy mainly consisted of the $\alpha^{\prime}+\beta$ phase $(50.61 \% \alpha$-phase and $49.39 \% \beta$-phase). When 3 wt. $\% \mathrm{Fe}$ or greater was added, the $\beta$ phase was entirely retained with a BCC crystal structure (1.08 \% $\alpha$-phase and $98.92 \% \beta$-phase) because the stabilizing effect of the beta phase by Fe is well known, as reported by Niinomi et al. [22]. 


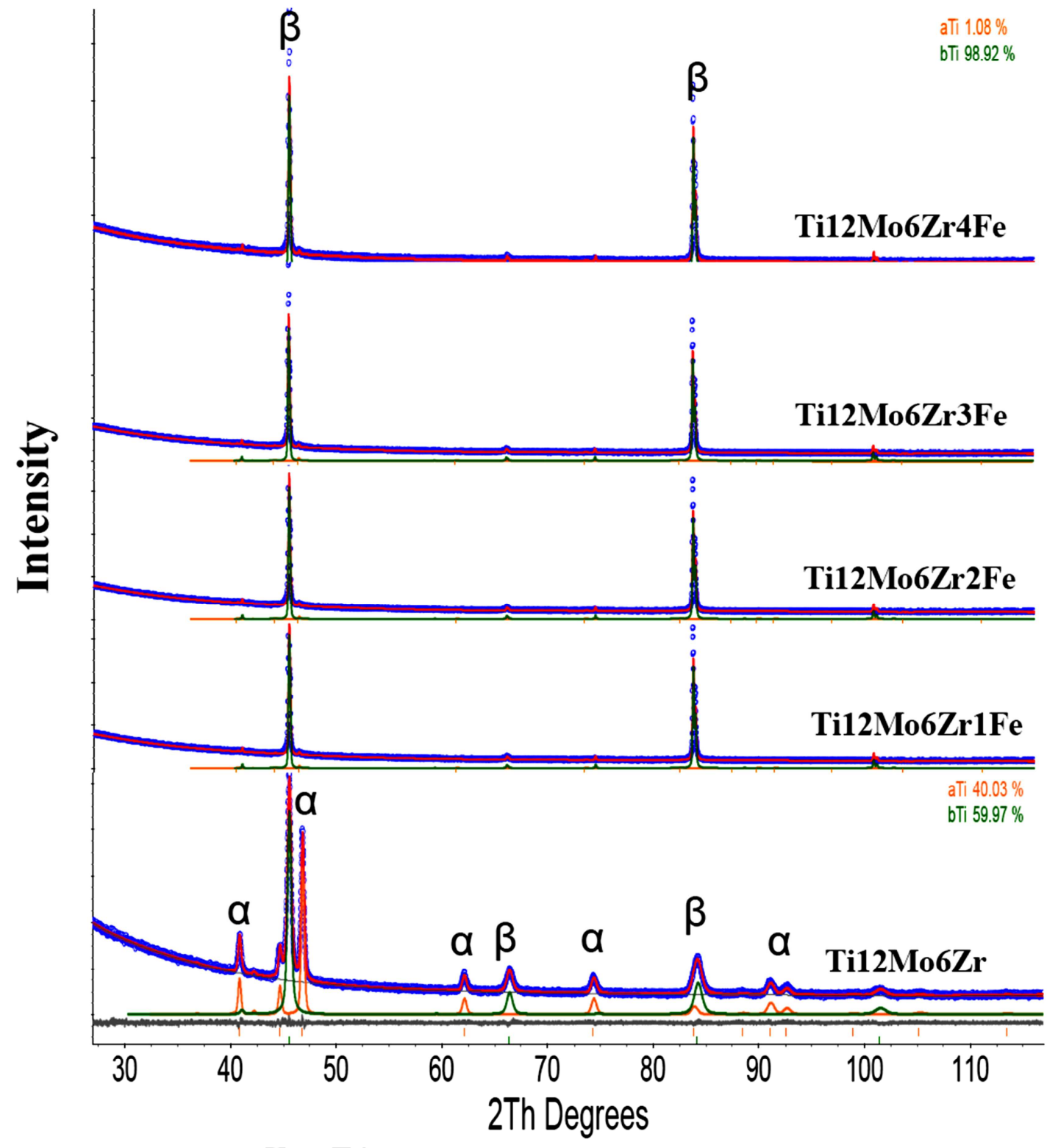

Fig. 2. XRD patterns for the sintering Ti12Mo6Zr and different addition of Fe alloys.

\subsection{Effect of sintering temperature and Fe content on relative density of Ti12Mo6Zr alloy.}

The relative density of the alloys had a close correlation with the Fe content and sintering temperature, as shown in Fig. 3. The result showed that the relative density decreased with increasing Fe content which is similar to those reported by Jue Liu et al. [42]. In addition, the relative densities showed an obvious increase with increasing sintering temperatures. Normally relative density is high in case of $1300{ }^{\circ} \mathrm{C}$ but for Ti12Mo6Zr2Fe, the value of relative density for $1300{ }^{\circ} \mathrm{C}$ is a little bit lower than 1250 ${ }^{\circ} \mathrm{C}$. 


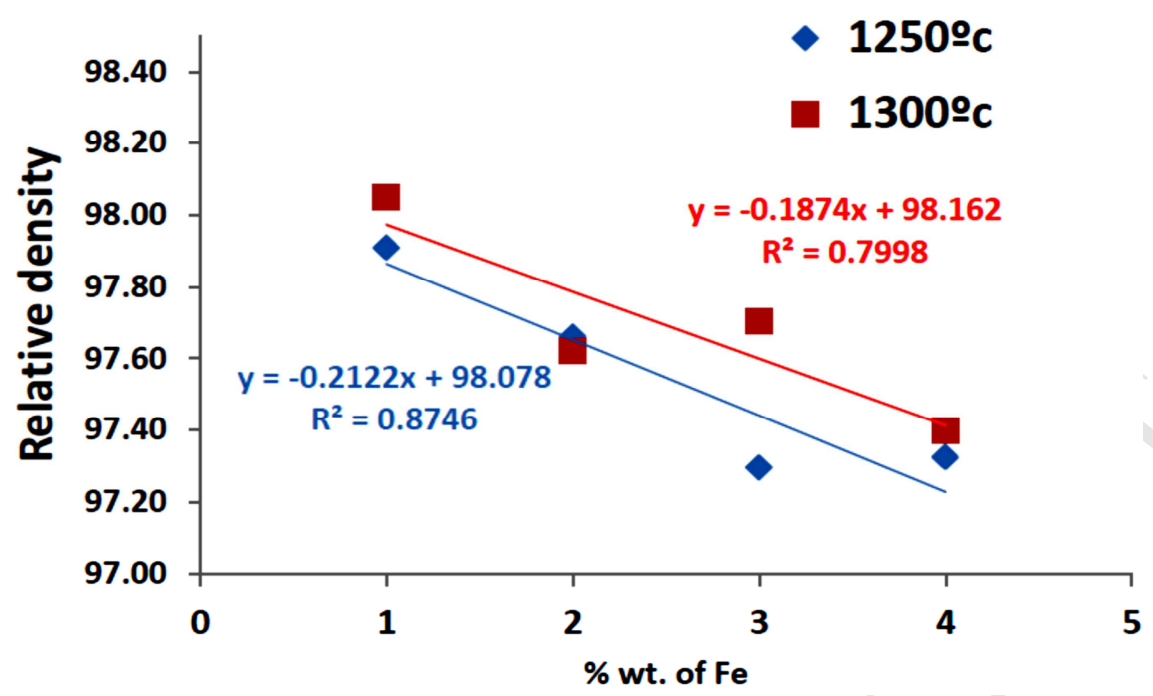

Fig. 3. Relative density of Sintered Ti12Mo6ZrxFe at $1250{ }^{\circ} \mathrm{C}$ and $1300{ }^{\circ} \mathrm{C}$ with different Fe contents.

\subsection{Effect of powder processing on total porosity and density of Ti12Mo6Zr2Fe alloy.}

Green density is a measurement of compaction quality and it's calculated just after compaction process and before sintering. Fig. 4 (a) show the green density of Ti12Mo6Zr2Fe alloy at different powder processing. It is clear that the Ti12Mo6Zr2Fe alloy with EB at $600 \mathrm{MPa}$ had a highest green density which is proper and homogeneous. In Fig. 4 (b), total porosity by MA technique at $600 \mathrm{MPa}$ is very high in comparison to $\mathrm{EB}$ technique, due to plastic deformation occurs in MA process. In addition, with increases compaction pressure from $600 \mathrm{MPa}$ to $900 \mathrm{MPa}$, the total porosity decreases about $30 \%$.
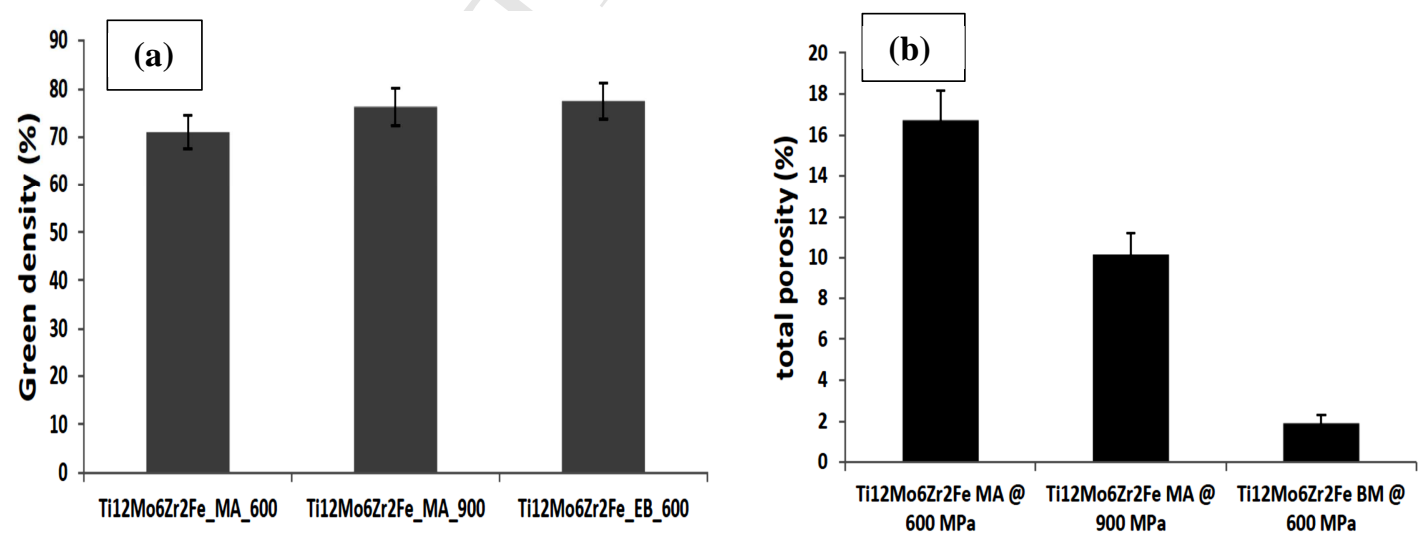

Fig. 4. (a) Green density calculated after compaction and (b) Total porosity calculated by Archemedis test. 


\subsection{Effect of sintering temperature and Fe content on microstructures (SEM/EDS) of Ti12Mo6ZrxFe alloy.}

Compositions of the series of Ti12Mo6ZrxFe alloys determined by scanning electron microscopy/energy dispersive spectrometry (SEM/EDS) are listed in Table 2. Fig. 5 shows the BSE-SEM micrographs of Ti12Mo6Zr and Ti12Mo6ZrxFe alloys. As shown in Fig. 5(a), the BSE-SEM micrograph of the Ti12Mo6Zr alloy appears $\alpha$ and $(\alpha+\beta)$ structure. In contrast to the Ti12Mo6ZrxFe alloy, the BSE-SEM micrographs of the other alloys appeared the consist of $\beta$ phase grains, as shown in Fig. 5 (b, c, d, and f). In other words, in the Ti-Fe alloy system, the $\beta$ phase can be entirely retained upon fast cooling when the Fe content increases. Table 2 show the average $\beta$ phase grain sizes of the Ti12Mo6Zr and Ti12Mo6ZrxFe series alloys, according to ASTM E 112 - 96 Standard Test Methods. The result shows that the average $\beta$ phase grain sizes decreased with increasing Fe content. Additionally, the grain size and phase distribution of the samples were obtained from SEM images using an image analysis program as shown in Table 3. As seen in the SEM images in Fig. 5 (f), the pore size and pore shape varied with sintering temperature gradually as well. At a higher sintering temperature of $1300{ }^{\circ} \mathrm{C}$, the pores were fewer and more regular in shape, whereas mostly irregular and bad degree of rounding pores were introduced with a relatively low sintering temperature of $1250{ }^{\circ} \mathrm{C}$. 


\section{ACCEPTED MANUSCRIPT}
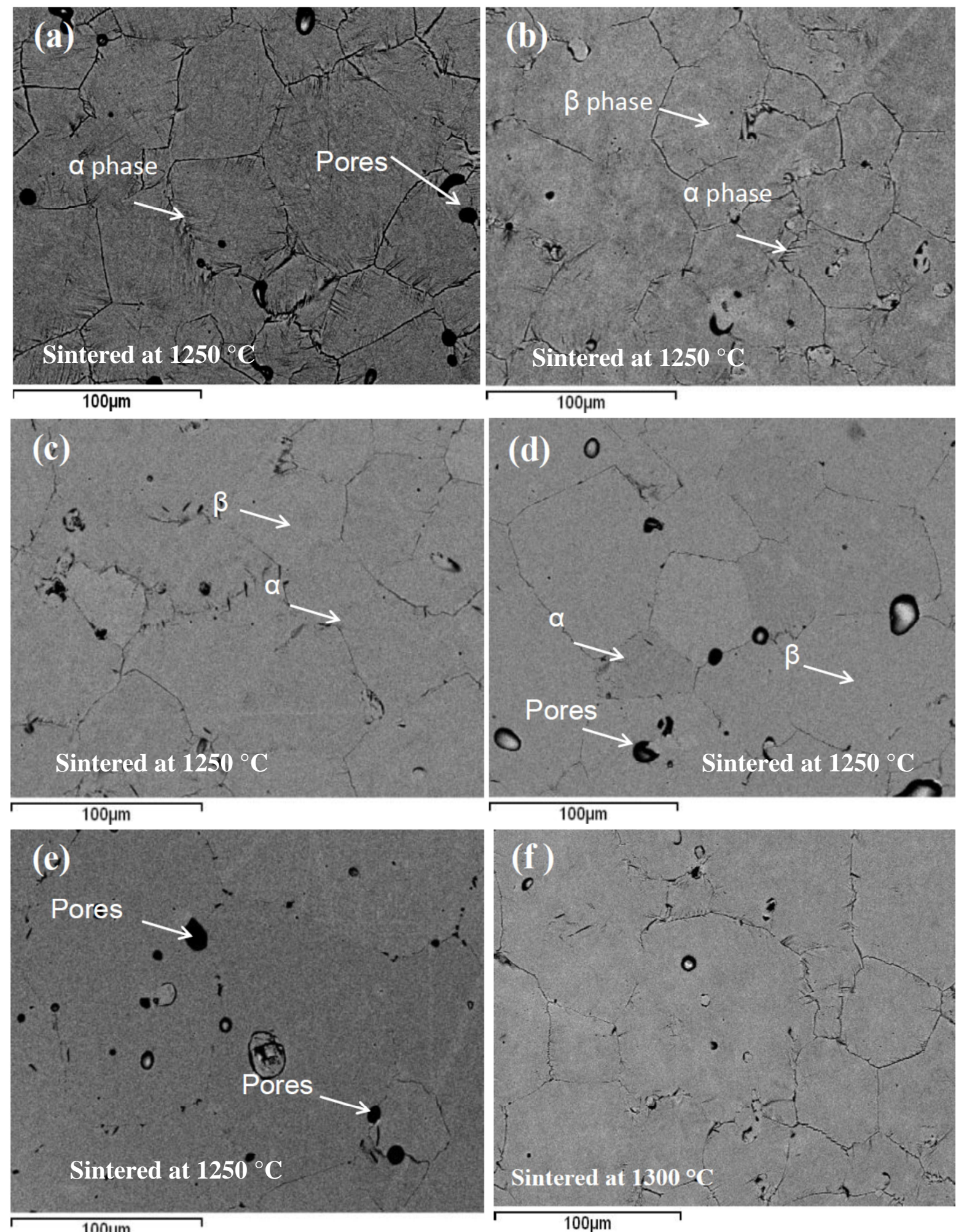

Fig. 5. BSE-SEM micrographs of alloys (a) Ti12Mo6Zr, (b) Ti12Mo6Zr1Fe, (c) Ti12Mo6Zr2Fe, (d) Ti12Mo6Zr3Fe, (e) Ti12Mo6Zr4Fe sintered at $1250{ }^{\circ} \mathrm{C}$ and (f) Ti12Mo6Zr2Fe sintered at $1300{ }^{\circ} \mathrm{C}$. 
Table 2: Elemental composition calculated by smart map analysis.

\begin{tabular}{|c|c|c|c|c|}
\hline Alloy code & Ti (wt. \%) & Mo (wt. \%) & $\mathrm{Zr}$ (wt. \%) & $\mathrm{Fe}($ wt. \%) \\
\hline Ti12Mo6Zr & $80.8 \pm 0.13$ & $12.78 \pm 0.05$ & $6.35 \pm 0.07$ & \\
\hline Ti12Mo6Zr1Fe & $79.68 \pm 0.18$ & $12.89 \pm 0.07$ & $6.49 \pm 0.08$ & $0.94 \pm 0.02$ \\
\hline Ti12Mo6Zr2Fe & $78.96 \pm 0.48$ & $12.75 \pm 0.42$ & $6.33 \pm 0.13$ & $1.95 \pm 0.06$ \\
\hline Ti12Mo6Zr3Fe & $77.70 \pm 0.21$ & $13.04 \pm 0.01$ & $6.43 \pm 0.12$ & $2.84 \pm 0.08$ \\
\hline Ti12Mo6Zr4Fe & $76.47 \pm 0.18$ & $13.18 \pm 0.23$ & $6.46 \pm 0.02$ & $3.9 \pm 0.04$ \\
\hline
\end{tabular}

Table 3: Relative density, grain size and phase distribution of each alloy composition by optical microscopy.

\begin{tabular}{|c|c|c|c|c|}
\hline Alloy code & $\begin{array}{l}\text { Relative density } \\
\qquad(\%)\end{array}$ & $\begin{array}{c}\beta \text { grain size } \\
(\mu \mathrm{m})\end{array}$ & $\begin{array}{l}\text { Phase } \\
\% \alpha \text {-phase }\end{array}$ & $\begin{array}{l}\text { distribution } \\
\% \beta \text {-phase }\end{array}$ \\
\hline Ti12Mo6Zr & $97.29 \pm 0.82$ & $\begin{array}{c}50.36 \pm \\
3.10\end{array}$ & $3.60 \pm 0.26$ & $96.40 \pm 0.26$ \\
\hline Ti12Mo6Zr1Fe & $97.89 \pm 0.33$ & $\begin{array}{c}46.66 \pm \\
2.40\end{array}$ & $1.30 \pm 0.23$ & $98.70 \pm 0.23$ \\
\hline Ti12Mo6Zr2Fe & $98.77 \pm 0.64$ & $\begin{array}{c}42.50 \pm \\
3.42\end{array}$ & $1.10 \pm 0.12$ & $98.90 \pm 0.12$ \\
\hline Ti12Mo6Zr3Fe & $97.86 \pm 0.34$ & $\begin{array}{c}43.92 \pm \\
1.55\end{array}$ & $1.20 \pm 0.15$ & $98.80 \pm 0.15$ \\
\hline Ti12Mo6Zr4Fe & $97.39 \pm 0.30$ & $\begin{array}{c}45.21 \pm \\
3.12\end{array}$ & $1.30 \pm 0.22$ & $98.70 \pm 0.22$ \\
\hline
\end{tabular}

A good distribution of the alloying elements is confirmed by EDX in these transition areas, as shown in Fig. 6. In this case, the gradient in the microstructure morphology along the sample's radial direction might be associated with the stability of the $\beta$ phase. A method based on the EBSD measurements was used to identify the phase transformation of the Ti12Mo6Zr2Fe alloy, as shown in Fig. 7. The microstructural parameters affect to mechanical properties, but the most important is the porosity. It affects bending strength and elastic modulus as well as the microstructure of the alloy. From Fig. 7(a), it is clearly shown that the particles are regular with a smaller shape and a lot of porosity appeared by using MA alloy which is better than EB alloys. On the other hand, for EB alloys (Fig. 7 (b)) the particles are not regular with less in porosity. 

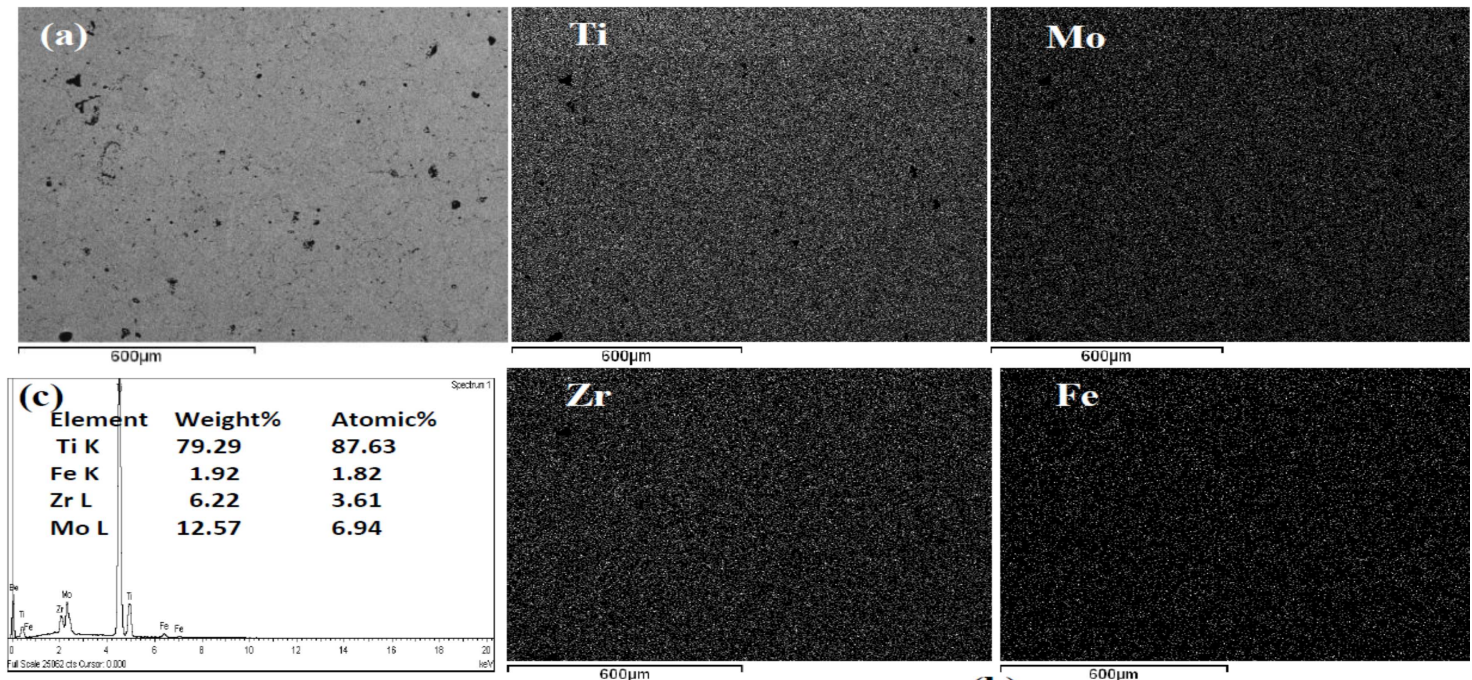

(b)

Fig. 6. High magnification SEM-BSE micrograph of the (a) Ti12Mo6Zr2Fe alloy showing a microstructure observed in a transition area within the microstructural gradient; (b) mapping analysis of the area, confirming a homogeneous distribution of the alloying elements; and (c) EDX.
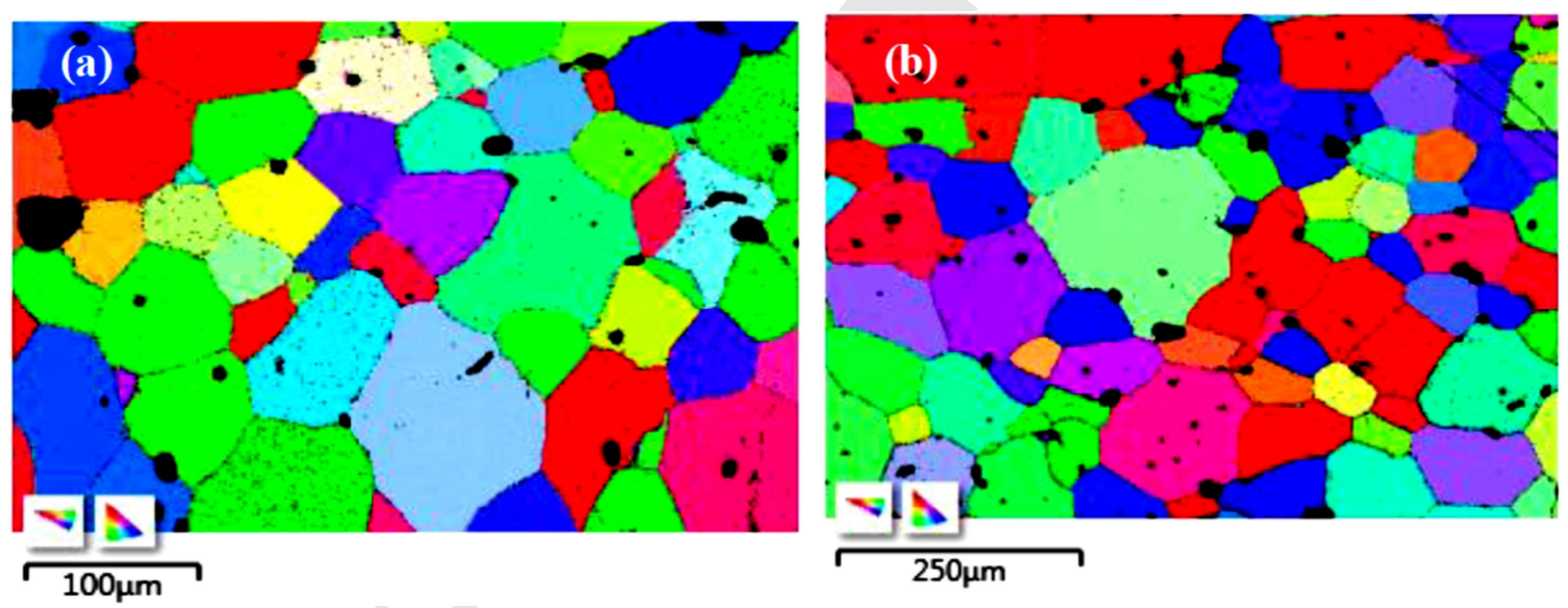

Fig. 7. IPF EBSD maps of Ti12Mo6Zr2Fe alloy showing the $\beta$ phase micro texture at phase transformation at different sintered temperature (a) MA, $1250{ }^{\circ} \mathrm{C}$ and (b) $\mathrm{EB}$, $1300{ }^{\circ} \mathrm{C}$.

\subsection{Effect of powder processing on microstructure of Ti12Mo6Zr2Fe alloy}

Fig. 8 shows the microstructure of powder processing techniques used for preparing Ti12Mo6Zr2Fe alloy. From Fig. 8(a) it's shown that a bigger porosity appears due to plastic deformation occurs in MA but when increasing the pressure for MA technique the pore size decreases, but the number of grain boundary increases as shown in Fig. 8 (b). In contrast, for EB technique as shown in Fig. 8(c) the grain size is very large in comparison to MA alloy and $\beta$-phase appears at the grain boundary of the alloy. 

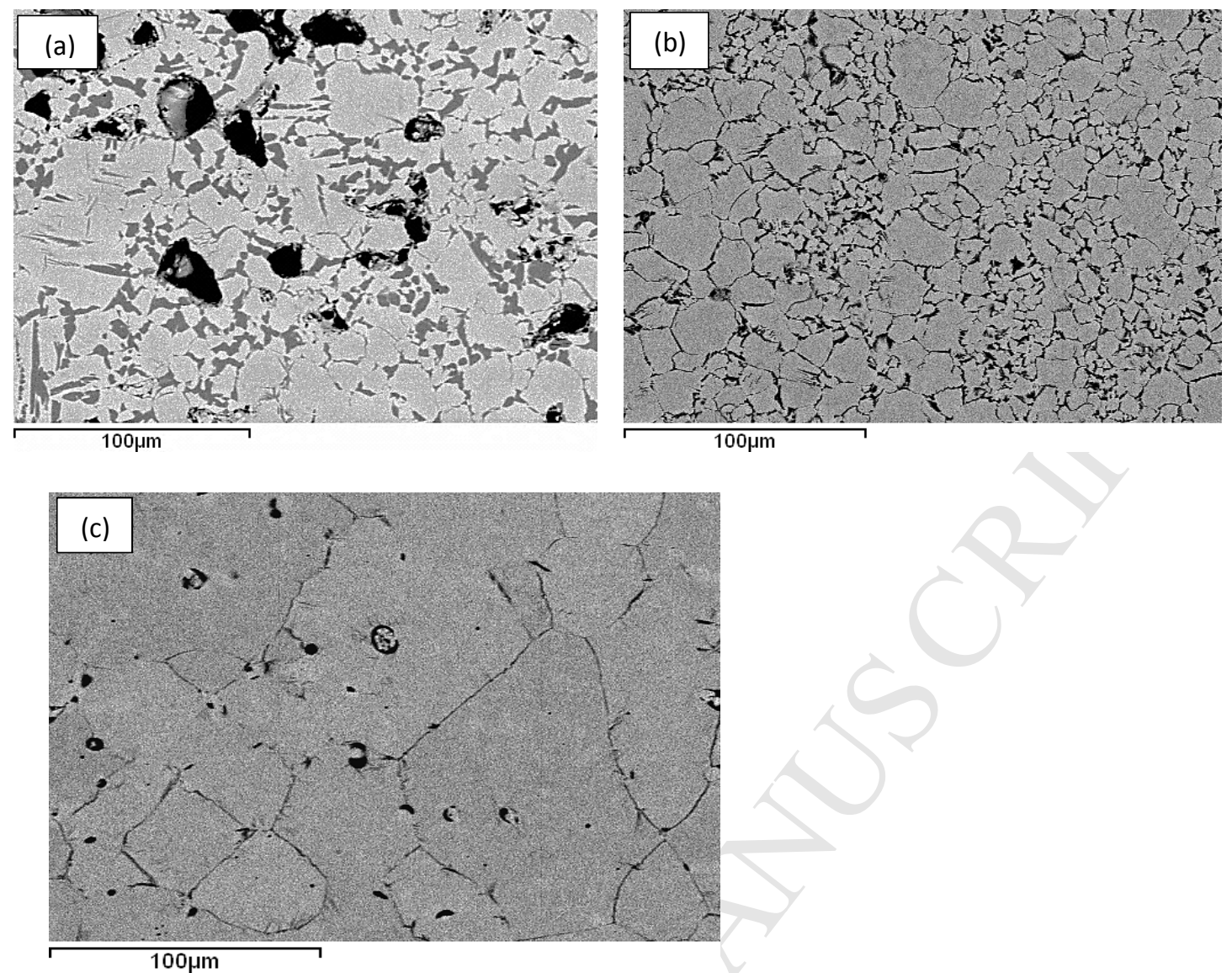

Fig. 8. Microstructure of Ti12Mo6Zr2Fe by: (a) Mechanical alloying method with $600 \mathrm{MPa}$ compaction pressure (b) Mechanical alloying method with $900 \mathrm{MPa}$ compaction pressure, and (c) Elemental blend method with $600 \mathrm{MPa}$ compaction pressure.

\subsection{Effect of sintering temperature and Fe content on mechanical properties of Ti12Mo6ZrxFe alloy.}

The variations of the bending strength, bending modulus, elastic moduli, and hardness of Ti12Mo6ZrxFe alloys with various $\mathrm{Fe}$ contents and sintering temperature are shown in Fig. 9. The typical bending and compression stress-strain curves of Ti12Mo6Zr and Ti12Mo6ZrxFe alloys are shown in Fig. 9 (a). In this study, all Ti15Mo6Zr and Ti12Mo6ZrxFe alloys exhibited ductile properties. However, from 14 wt. $\% \mathrm{Fe}$, retention of the metastable $\beta$ phase began. The results of the elastic modulus are very important for biomaterials, and the elastic modulus should be closer to that of human bone [43]. With increasing Fe content, the bending strength of the Ti12Mo6ZrxFe alloys showed a rapid decrease as shown in Fig 9 (b). When Fe content was 1 wt.\%, the corresponding bending strength was $1700 \mathrm{MPa}$. But the bending strength went down to $650 \mathrm{MPa}$ when the Fe content increased up to 4 wt. $\%$. For Ti12Mo6Zr2Fe alloy sintered at $1250{ }^{\circ} \mathrm{C}$, the bending strength reached 1200 $\mathrm{MPa}$, and then increased to the highest level of $1400 \mathrm{MPa}$ after sintered at $1300{ }^{\circ} \mathrm{C}$, as shown in Fig. 9 (b). In addition, as shown in Fig. 9(c), the bending modulus decreased from $39 \mathrm{GPa}$ to $32 \mathrm{GPa}$ with increasing Fe content from 1 to $4 \mathrm{wt} \%$ for the alloys sintered at $1250{ }^{\circ} \mathrm{C}$ and $1300{ }^{\circ} \mathrm{C}$, respectively. Obviously, a decrease in hardness could be also found with increasing Fe content, and Ti12Mo6Zr4Fe alloy displayed 
the lowest hardness value. Otherwise, the highest hardness value was acquired for Ti12Mo6Zr1Fe alloy, as shown in Fig. 9(d). Hard tissue replacement (HTR) materials usually work in elastic deformation conditions. The work done by an external force can store in the alloy as energy in deformation process and the energy release when the external force decreases. For a better understanding of the mechanical behaviors of the HTR materials, elastic energy should be well investigated. The elastic energy of the Ti12Mo6Zr $x$ Fe alloys ranged from $7.13 \mathrm{~J}$ to $23.92 \mathrm{~J}$, which is in the range of reported Ti12Mo6Zr based alloys (36 J), as shown in Fig. 6(f). According to the results, TiMoZr $x$ Fe alloys could withstand the elastic deformation.
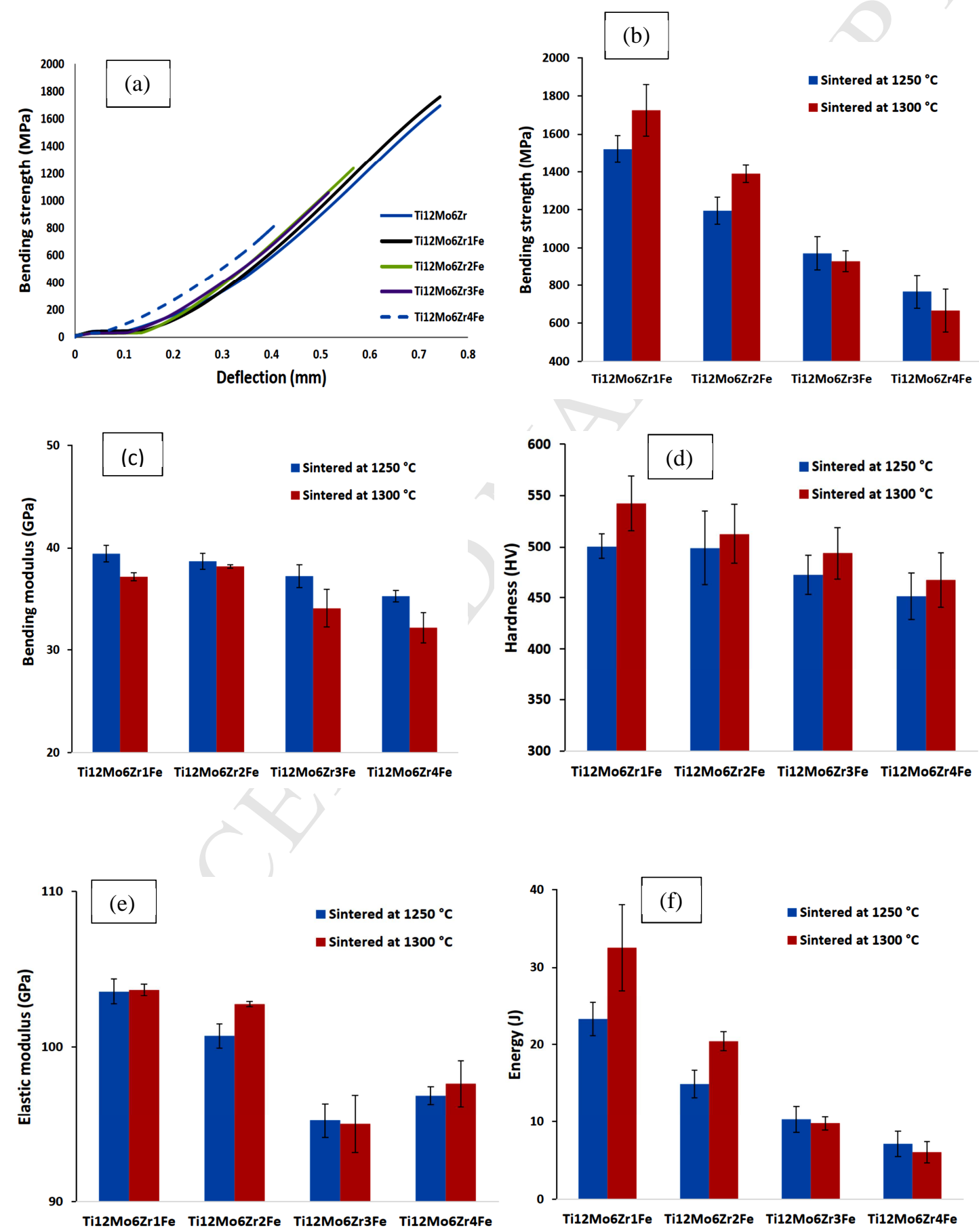
Figure 9. (a) Bending stress-strain curves of Ti12Mo6Zr and Ti12Mo6Zr $x$ Fe alloys sintered at $1250{ }^{\circ} \mathrm{C}$, (b) Bending strength, (c) Bending modulus, (d) hardness, (e) Elastic modulus and (f) Energy as a function of the Fe content of Ti12Mo6Zr $x \mathrm{Fe}$ alloys sintered at $1250{ }^{\circ} \mathrm{C}$ and $1300{ }^{\circ} \mathrm{C}$.

\subsubsection{Effect of powder processing on mechanical properties of Ti12Mo6Zr2Fe alloy.}

The typical bending stress-strain curves of Ti12Mo6Zr2Fe alloys at different powder process are shown in Fig. 10 (a). In the case of EB technique bending strength is 2-3 times higher than the MA technique. EB alloy has good strength (800-850 MPa) in comparison to MA (300-600 MPa). The increase of compaction pressure from 600 $\mathrm{MPa}$ to $900 \mathrm{MPa}$ also enhances the bending strength from $329 \mathrm{MPa}$ to $637 \mathrm{MPa}$ (approx. 95\%). In the case of MA due to high porosity, bending strength is very less, where we represent bending strength versus $\ln (1 /$ Internal Porosity). The maximum bending strength for human cortical bone is $110-184 \mathrm{MPa}$ [22], which is much less than bending strength found in the present work. Bending strength increases with the inverse of internal porosity means that internal porosity affects bending strength in inverse order, which is clearly shown in Fig. 10 (c). Bending strength increases with increase in the percentage of $\beta$-phase, which is clearly shown in Fig. 10 (d). In the case of MA, the percentage of $\beta$-phase is less than EB alloy. For EB alloy $\alpha$-phase found only on the grain boundary of the alloy.
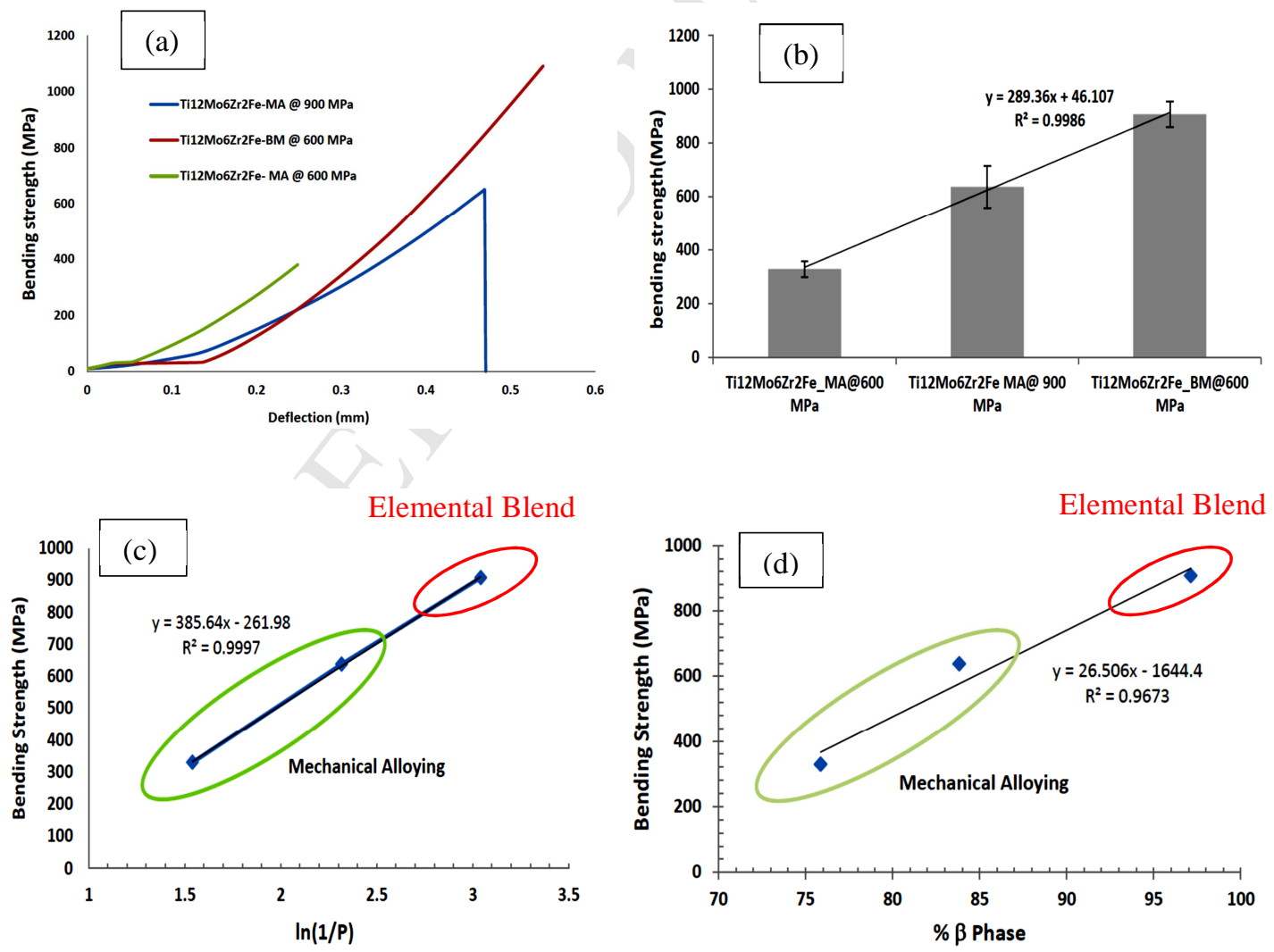

Fig. 10. (a) Bending stress-strain curves of Ti12Mo6Zr2Fe alloys at different powder process, (b) Bending strength of Ti12Mo6Zr2Fe alloys, (c) Bending strength vs $1 /$ internal porosity and (d) Bending strength vs $\% \beta$-phase. 
Elastic modulus is the main mechanical property for the design of biomaterials by Ultrasonic test as shown in Fig. 11(a). The result indicated that the elastic modulus for MA is less in comparison to EB alloy. This may be due to the total porosity of alloys, as elastic modulus increases when porosity is low. The value of elastic modulus for EB alloy is higher than MA alloy. Elastic modulus for Ti12Mo6Zr2Fe (annealed) is 74-85 MPa [23], which is comparable to Ti12Mo6Zr2Fe alloy prepared by the mechanical alloying method with $900 \mathrm{MPa}$ compaction pressure. Modulus of elasticity determined with MA at $600 \mathrm{MPa}$ gives the least value, which signifies better for use as a biomaterial. Modulus of elasticity for cortical bone is generally between 17 and $28 \mathrm{GPa}$ [24], which is much smaller than the elastic modulus found in the present work. So, there is a requirement of reducing the value of elastic modulus. The relation between bending and elastic modulus, then the nature of the graph is linear, that means bending strength is directly proportional to elastic modulus, as shown in Fig. 11 (b), with a square correlation 0.99 . Internal porosity affects bending strength in inverse order that means the relation between bending strength and the inverse of internal porosity, bending strength increases. So, bending strength is minimum in case of MA due to high internal porosity, as shown in figure 11 (c). The graph shows the effect of internal porosity on elastic modulus, it is clear that internal porosity affects, but shows linear nature with logarithmic of internal porosity, square correlation more than 0.999 (Fig. 11(c)).
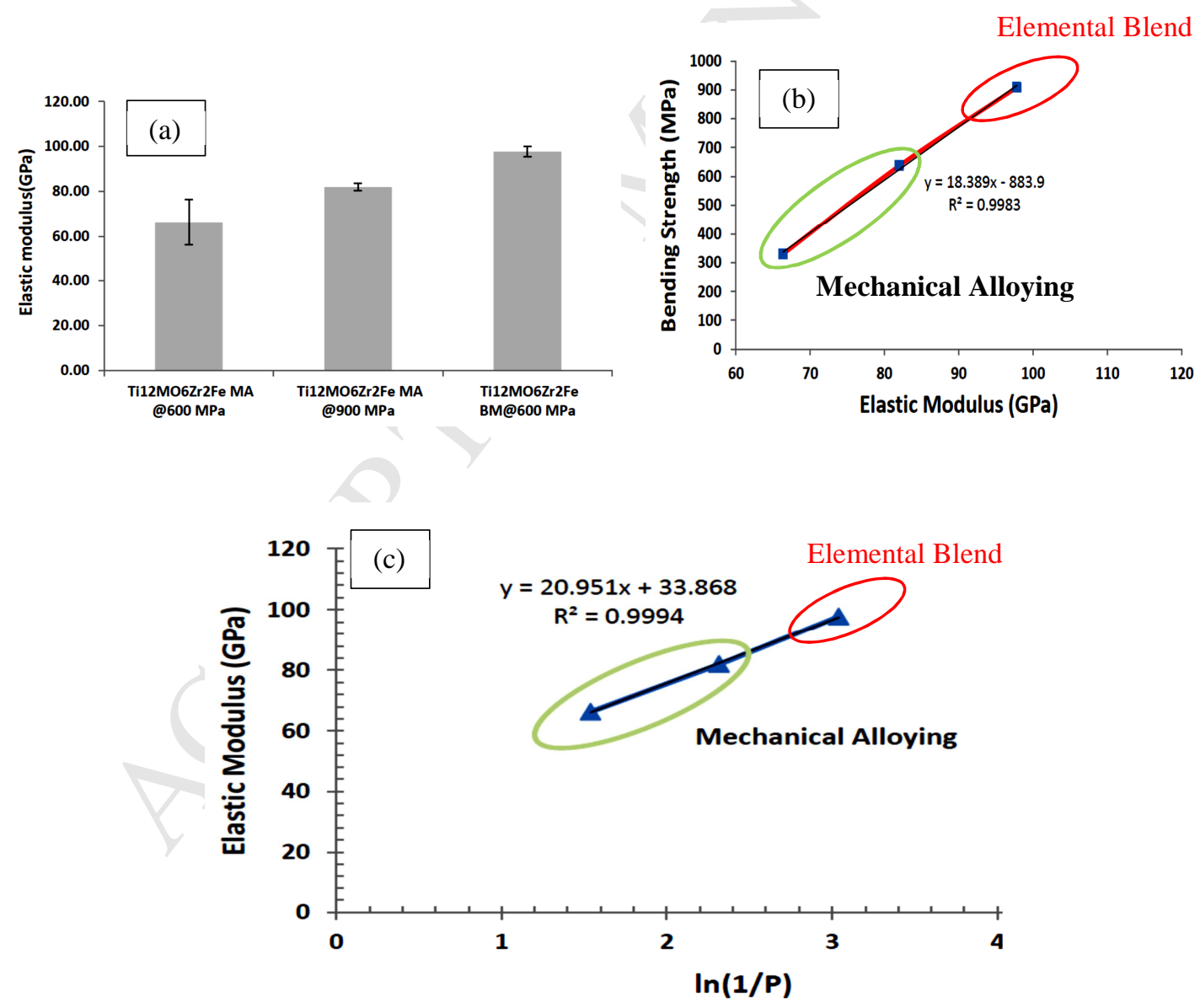

Fig. 11. (a) Elastic modulus of Ti12Mo6Zr2Fe alloys at different powder process, (b) Bending modulus of Ti12Mo6Zr2Fe alloys at different powder process vs Elastic modulus and (c) Elastic modulus vs 1/internal porosity. 


\subsection{Fracture Surface}

Fig. 12 shows that fractography of Ti12Mo6Zr2Fe with both method elemental blend and mechanical alloying. Due to high porosity found in MA, it shows intragranular fracture with the brittle character which is shown in figure 7(a). In addition, elemental blend shows a mixed type of fracture (brittle and ductile both) as shown in figure 8(b). Moreover, elongation in the case of elemental blend alloy is more than mechanical alloying alloy. This result is in accordance with the change in the lower value of bending deflection (less than approximately 0.6). The effect of the iron content and $\beta$ phase on Ti12Mo6Zr-based alloy can also be observed in fractography of this alloy. Figure 13 (a-e) shows SEM micrographs of the fractured surfaces of Ti12Mo6Zr and Ti12Mo6ZrxFe sintered at $1300{ }^{\circ} \mathrm{C}$ after bending tests. As shown in Fig. 13a, Ti12Mo6Zr was characterized ductile fracture in the fractured surface, which is indicative of a typical ductile fracture. The fractured structures of Ti12Mo6Zr1Fe (Fig. 13b) consist of a few dimples and cleavage planes, meaning that the fracture process of this alloy is a mixture of brittle and plastic mechanisms. As shown in Fig. $13 \mathrm{c}$, the fractured structures of the Ti12Mo6Zr2Fe alloy exhibited mainly dimple ruptures and a few cleaved grains, which is indicative of a typical ductile fracture. Compared with Ti12Mo6Zr1Fe, the cleavage planes of Ti12Mo6Zr3Fe (Fig. 13d) and Ti12Mo6Zr4Fe (Fig. 13e) increase in size, indicating that the latter is more brittle than the former, which is characteristic of the decreased ductility. The cleavage fracture corresponds to the brittleness of the specimen. This result is in accordance with the change in the lower value of bending deflection (less than approximately 0.8 $\mathrm{mm})$. When the sintered temperature increase, the fractured structures of Ti12Mo6Zr2Fe (Fig.13f) sintered at $1300{ }^{\circ} \mathrm{C}$ consist of a dimples and cleavage planes, meaning that the fracture process of this alloy is a mixture of brittle and plastic mechanisms.
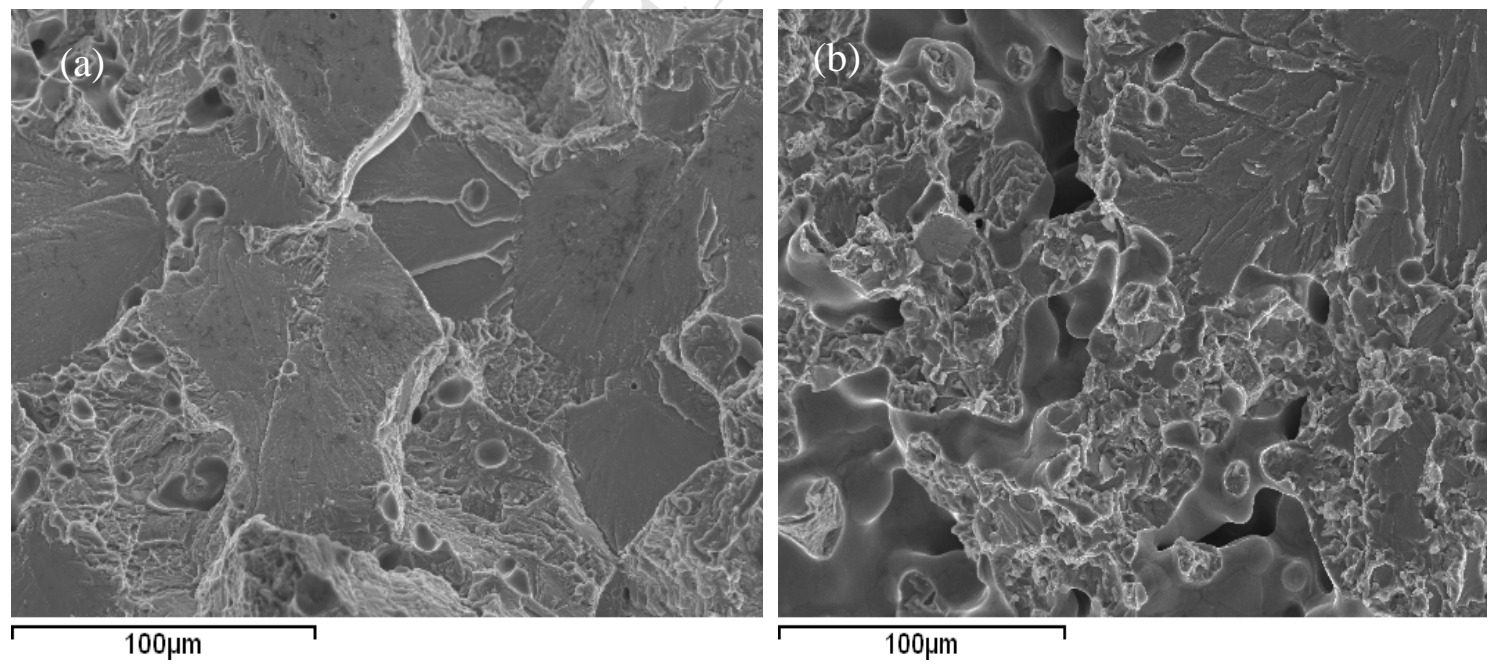

Fig.12. Fractography image of Ti12Mo6Zr2Fe with: (a) MA method under $900 \mathrm{MPa}$ compaction pressure, and (b) BM method under $600 \mathrm{MPa}$ compaction pressure 

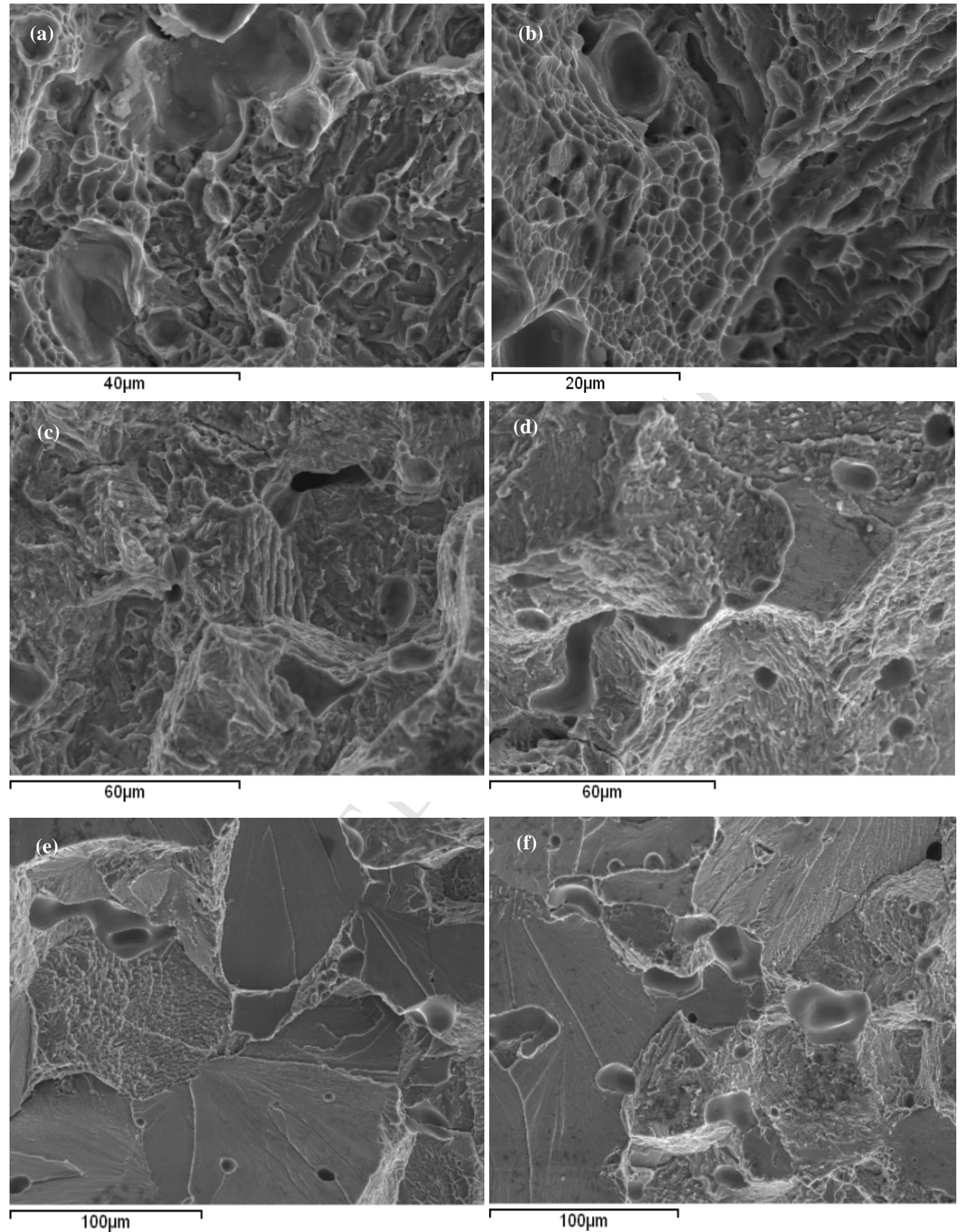

Fig. 13. SEM fractography of (a) Ti12Mo6Zr, (b) Ti12Mo6Zr1Fe, (c) Ti12Mo6Zr2Fe, (d) Ti12Mo6Zr3Fe, and (e) Ti 12Mo 6Zr4Fe alloys sintered at 1250 ${ }^{\circ} \mathrm{C}$ and (f) Ti12Mo6Zr2Fe sintered at $1300{ }^{\circ} \mathrm{C}$. 


\section{ACKNOWLEDGEMENTS}

The authors would like to thank the SME (Electron Microscopy Service) of the Universitat Politècnica de València (UPV) - Spain, the Spanish Ministry of Economy and Competitiveness under the Research Project MAT2014-53764-C3-1-R, and the European Commission due to the FEDER funds.

\section{Conclusion}

Ti12Mo6ZrxFe ( $\mathrm{x}=1,2,3$ and $4 \mathrm{wt} . \%)$ alloys were fabricated by powder metallurgy technique. The result indicated that the elastic modulus decrease from $105 \mathrm{GPa}$ to 93 GPa with the addition of Fe. In addition, insufficient dissolution occurred during the sintering Ti12Mo6Zr2Fe alloys below $1300{ }^{\circ} \mathrm{C}$. Moreover, the addition of $\mathrm{Fe}$ increases $\beta$-phase stability for Ti12Mo6Zr alloy. Ti12Mo6Zr2Fe prepared by mechanical alloying technique shows more porosity in comparison to elemental blend alloy at the same sintering parameters. By increasing the compaction pressure, compaction results found better in the case of MA. For MA, plastic deformation is the main cause of high porosity and due to high porosity mechanical properties for MA is inferior to the EB alloy. Fractography shows a mixed type of fracture in case of EB alloy like brittle and ductile. For MA samples, due to high porosity intragagranular fracture with brittle fracture appears. From SEM study it is clear that MA samples have more $\alpha$ phase in comparison to EB samples. $\alpha$-phase appears inside the alloy for MA samples and for the EB alloy $\alpha$-phase appears on grain boundary. Finally, Ti-Mo$\mathrm{Zr}-\mathrm{Fe}$ alloys are quite promising as a new candidate of biomedical materials with appropriate mechanical and biological properties.

\section{Conflict of interest:}

The authors declare that they have no conflict of interest.

\section{References:}

[1] X.X. Ye, B. Chen, J.H. Shen, J. Umeda, K. Kondoh" Microstructure and strengthening mechanism of ultrastrong and ductile Ti-xSn alloy processed by powder metallurgy" Journal of Alloys and CompoundsVolume 709, 30 June 2017, Pages 381393.

[2] B.Q. Li, C.Y. Wang, X. Lu" Effect of pore structure on the compressive property of porous $\mathrm{Ti}$ produced by powder metallurgy technique" Materials and Design 50 (2013) 613-619.

[3] Lucía Reig, Concepción Tojal , David J. Busquets and Vicente Amigó "Microstructure and Mechanical Behavior of Porous Ti-6Al-4V Processed by Spherical Powder Sintering" Materials 2013, 6, 4868-4878; doi:10.3390/ma6104868.

[4] M. Niinomi, "Biologically and mechanically biocompatible titanium alloys", Mater Trans, 49 (2008) 2170-8.

[5] Alaa Mohamed, El-Sayed R, T.A. Osman, M.S. Toprak, M. Muhammed, A. Uheida, "Composite nanofibers for highly efficient photocatalytic degradation of organic dyes from contaminated water" Environmental Research. 145(2016)18-25.

[6] C. Li, Y. Zhan, W. Jiang, "Beta-type Ti-Mo-Si ternary alloys designed for biomedical applications", Mater Des, 34 (2012) 479-82. 
[7] Xueyuan Yang, Christopher R. Hutchinson "Corrosion-wear of $\beta$-Ti alloy TMZF (Ti-12Mo-6Zr-2Fe) in simulated body fluid", Acta Biomaterialia, 42(2016) p. 429-439.

[8] Alaa Mohamed, T.A. Osman, M.S. Toprak, M. Muhammed, A. Uheida, "Surface functionalized composite nanofibers for efficient removal of arsenic from aqueous solutions" Chemosphere, 180, 2017, 108-116.

[9] M. Long, H.J. Rack, "Titanium alloys in total joint replacement-A materials science perspective", Biomaterials, 19 (1998) 1621-1639.

[10] M. Niinomi, "Recent metallic materials for biomedical applications", Metall. Mater. Trans., 33, A (2002) 477-486.

[11] Ho W-F, Chen W-K, Wu S-C, Hsu H-C. "Structure, mechanical properties, and grindability of dental Ti-Zr alloys." J Mater SciMater Med 2008;19: 3179-86.

[12] F.G. Evans, "Mechanical properties and histology of cortical bone from younger and older men", Anat. Rec., 185 (1976) 1-11.

[13] Alaa Mohamed, Samy Yousef, Mohammed Ali Abdelnaby, T.A. Osman, B. Hamawandi, M.S. Toprak, M. Muhammed, A. Uheida, "Photocatalytic degradation of organic dyes and enhanced mechanical properties of PAN/CNTs composite nanofibers" Separation and Purification Technology, 182 (2017) 219-223.

[14] J.Y. Rho, T.Y. Tsui, G.M. Pharr, "Elastic properties of human cortical and trabecular lamellar bone measured by nanoindentation”, Biomaterials, 18 (1997) 1325-1330.

[15] Alaa Mohamed, W.S. Nasser, T.A. Osman, M.S. Toprak, M. Muhammed, A. Uheida, "Removal of chromium (VI) from aqueous solutions using surface modified composite nanofibers" Journal of Colloid and Interface Science, 505 (2017), 682-691.

[16] Hsu H-C, Wu S-C, Sung Y-C, Ho W-F. "The structure andmechanical properties of as-cast Zr-Ti alloys." J Alloys Compd 2009;488: 279-83.

[17] D. Kuroda, M. Niinomi, M. Morinaga, Y. Kato, T. Yashiro, "Design and mechanical properties of new $\beta$ type titanium alloys for implant materials", Mater. Sci. Eng., 243, A (1998) 244-249.

[18] Ho WF, Ju CP, Chern Lin JH. Structure and properties of castbinary Ti-Mo alloys. Biomaterials 1999;20: 2115-22.

[19] S. Nag, R. Banerjeeb, H.L. Fraser" Microstructural evolution and strengthening mechanisms in $\mathrm{Ti}-\mathrm{Nb}-\mathrm{Zr}-\mathrm{Ta}, \mathrm{Ti}-\mathrm{Mo}-\mathrm{Zr}-\mathrm{Fe}$ and $\mathrm{Ti}-15 \mathrm{Mo}$ biocompatible alloys" Materials Science and Engineering C 25 (2005) 357 - 362.

[20] Y.L. Hao, M. Niinomi, D. Kuroda, K. Fukunaga, Y.L. Zhou, R. Yang, "Aging response of the Young's modulus and mechanical properties of Ti-29Nb-13Ta-4.6Zr." Metall. Mater. Trans., 34, A (2003) 1007-1012.

[21] N. Sakaguchi, M. Niinomi, T. Akahori, J. Takeda, H. Toda, "Relationship between tensile deformation behavior and microstructure in Ti-Nb-Ta-Zr", Mater. Sci. Eng., 25, C (2005) 363-369.

[22] M. Niinomi, T. Akahori, S. Katsura, K. Yamauchi, M. Ogawa, "Mechanical characteristics and microstructure of drawn wire of $\mathrm{Ti}-29 \mathrm{Nb}-13 \mathrm{Ta}-4.6 \mathrm{Zr}$ for biomedical applications", Mater. Sci Eng., 27, C (2007) 154-161.

[23] D. Kuroda, H. Kawasaki, A. Yamamoto, S. Hiromoto, T. Hanawa, "Mechanical properties and microstructures of new Ti-Fe-Ta and Ti-Fe-Ta-Zr system alloys", Mater. Sci. Eng., 25, C (2005) 312-320

[24] Alaa Mohamed, T.A. Osman, M.S. Toprak, M. Muhammed, Eda Yilmaz, A. Uheida, "Visible light photocatalytic reduction of $\mathrm{Cr}(\mathrm{VI})$ by surface modified CNT/Titanium dioxide composites nanofibers" Journal of Molecular Catalysis A: Chemical 424 (2016) 45-53. 
[25] EN ISO-3325.2000. Sintered metal materials, excluding hardmetals. Determination of transverse rupture strength

[26] I.H. Oh, N. Nomura, N. Masahashi, S. Hanada, "Mechanical properties of porous titanium compacts prepared by powder sintering", Scripta Mater., 49 (2003) 1197-1202.

[27] M. Niinomi, "Mechanical properties of biomedical titanium alloys", Mater. Sci. Eng., 243, A (1998) 231-236.

[28] J.A. Davidson, F.S. Gergette, "State of the art materials for orthopedic prosthetic devices, Proc. Implant Manufacturing and Material Technology", Soc. Manufact. Eng., Em87-122 (1986) 122-26.

[29] Abou Bakr Elshalakany, Shady Ali, A. Amigo' Mata, Ashraf K. Eessaa, P. Mohan, T.A. Osman, and V. Amigo' Borra' s "Microstructure and Mechanical Properties of Ti-Mo-Zr-Cr Biomedical Alloys by Powder Metallurgy". J. Mater. Eng. Perform (2017) 26:1262-1271.

[30] Lee CM, Ho WF, Ju CP, Chern Lin JH. Structure and properties of titanium-25 niobium-x iron alloys. J Mater Sci Mater Med 2002;13:695-700.

[31] Ho WF, Pan CH, Wu SC, Hsu HC. Mechanical properties and deformation behavior of Ti-5Cr-xFe alloys. J Alloy Compd 2009;472:546-50

[32] M. Long, H.J. Rack, "Titanium alloys in total joint replacement-A materials science perspective", Biomaterials, 19 (1998) 1621-1639.

[33] M. Niinomi, "Recent metallic materials for biomedical applications", Metall. Mater. Trans., 33, A (2002) 477-486.

[34] F.G. Evans, "Mechanical properties and histology of cortical bone from younger and older men", Anat. Rec., 185 (1976) p.1-11.

[35] O. Lindahl, A.G. Lindgren, "Cortical bone in man II. Variation in tensile strength with age and Sex", Acta Orthop. Scand., 38 (1967) p.141-147

[36] J.Y. Rho, T.Y. Tsui, G.M. Pharr, "Elastic properties of human cortical and trabecular lamellar bone measured by nanoindentation", Biomaterials, 18 (1997) p. $1325-1330$.

[37] O. Lindahl, "Mechanical Properties of Dried Defatted Spongy Bone", Acta Orthop. Scand, 47(1976) p.11-19

[38] M. Ding, M. Dalstra, C.C. Danielsen, J. Kabel, I. Hvid, F. Linde, "Age variations in the properties of human tibial trabecular bone", J. Bone J. Surg., 79 (1997) p. 995-1002.

[39] S. Gross, E.W. Abel, "A finite element analysis of hollow stemmed hip prostheses as a means of reducing stress shielding of the femur", J. Biomech., 34 (2001) p.995-1003.

[40] Hsueh-Chuan Hsu, Shih-Kuang Hsu, Shih-Ching Wu, Chih-Jhan Lee, Wen-Fu Ho "Structure and mechanical properties of as-cast $\mathrm{Ti}-5 \mathrm{Nb}-\mathrm{xFe}$ alloys", Materials Characterization 61 (2010) 851-858.

[41] S. Ehtemam-Haghighi, K.G. Prashanth, H. Attar, A.K. Chaubey, G.H. Ca, L.C. Zhang " Evaluation of mechanical and wear properties of TixNb7Fe alloys designed for biomedical applications" Materials and Design 111 (2016) 592-599.

[42] Jue Liu, Lin Chang, Hairong Liu, Yongsheng Li, Hailin Yang, Jianming Ruan" Microstructure, mechanical behavior and biocompatibility of powder metallurgy Nb-Ti-Ta alloys as biomedical material" Materials Science and Engineering C 71 (2017) 512-519.

[43] Mitsuo Niinomi, Yi Liu, Masaki Nakai, Huihong Liu, and Hua Li, "Biomedical titanium alloys with Young's moduli close to that of cortical bone", Regen Biomater. 2016 Sep; 3(3): 173-185. 
HIGHLIGHTS for the work entitled:

Effect of $\mathrm{Fe}$ content, sintering temperature and powder processing on the microstructure, fracture and mechanical behaviours of Ti-Mo-Zr-Fe alloys

According to the obtained results, the following itemized highlights can be stated:

- Addition of $\mathrm{Zr}$ and a small amount of Fe improves the $\beta$ stability of Ti-Mo alloy.

- The Ti12Mo6Zr2Fe alloys exhibited higher bending strength/modulus ratios

- Bending strength in EB is much higher than MA techniques.

- The microstructure of the alloys exhibited stable and metastable $\beta$ phase. 